Available online at
Elsevier Masson France

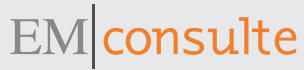

www.em-consulte.com/en

\title{
Mast cell-mediated splanchnic cholestatic inflammation
}

\author{
María-Ángeles Aller ${ }^{a, *}$, Vicente Martínez ${ }^{\mathrm{b}}$, Ana Arias ${ }^{\mathrm{c}}$, \\ Maria-Paz Nava ${ }^{d}$, Valentín Cuervas-Mons ${ }^{c}$, Patri Vergara ${ }^{b, e}$, \\ Jaime Arias ${ }^{a}$
}

\author{
a Department of Surgery, School of Medicine, Complutense University of Madrid, 28040 Madrid, Spain \\ ${ }^{b}$ Department of Cell Biology, Physiology and Immunology, Veterinary School, Autonoma University of \\ Barcelona, 08193 Cerdanyola del Vallès, Spain \\ c Department of Medicine, Autonoma University of Madrid, Hospital Puerta de Hierro. 28222 Madrid, Spain \\ d Department of Genetic, Physiology and Microbiology, Complutense University of Madrid, 28040 Madrid, \\ Spain \\ e Centro de Investigación Biomédica en Red de Enfermedades Hepáticas y Digestivas (CIBERehd), Instituto \\ de Salud Carlos III, Barcelona, Spain
}

\section{KEYWORDS \\ Cholestasis; \\ Mast cells; \\ Portal hypertension; \\ Ascites}

\begin{abstract}
Summary
Introduction: Splanchnic mast cells increase in chronic liver and in acute-on-chronic liver diseases. We administered Ketotifen, a mast cell stabilizer, and measured the mast cells in the splanchnic organs of cholestatic rats.

Material and Methods: These groups were studied: sham-operated rats $(S ; n=15)$, untreated microsurgical cholestasic rats $(C ; n=20)$ and rats treated with Ketotifen: early (SK-e; $n=20$ and CKe; $n=18)$, and late (SK-l; $n=15$ and CK-l; $n=14)$.

Results: The cholestatic rats showed systemic and splanchnic impairments, such as ascites, portal hypertension, and biliary proliferation and fibrosis. The rats also showed a splanchnic increase of TNF- $\alpha$, IL-1 $\beta$ and MCP-1, and a reduction of IL-4, IL-10 and antioxidants. An increase of VEGF in the ileum and mesenteric lymphatic complex was associated with a liver reduction of TGF- $\beta 1$. Ketotifen reduces the degree of hepatic insufficiency and the splanchnic inflammatory mediators, as well as VEGF and TGF- $B 1$ levels. Ketotifen also reduces the connective tissue
\end{abstract}

Abbreviations: ALT, alanine aminotransferase; AP, alkaline phosphatase; AST, aspartate aminotransferase; FGF, fibroblastic growth factor; BW, body weight; CTMCs, connective tissue mast cells; HDL-C, high density lipoprotein; LDL-C, low density lipoproteins; LW, liver weight; MMCs, mucosal mast cells; MCP-1, monocyte chemoattractant protein-1; NEFAs, non-esterified fatty acids; PP, Portal vein pressure; RMCP-II, rat mast cell proteinases 2 ; SW, spleen weight; TB, total bilirubin; TGF- $\beta 1$, Transforming growth factor beta 1 ; Treg, regulatory T-cell; VLDL, very low density lipoproteins; VCU, villus-crypt units; VEGF, vascular endothelium growth factor.

* Corresponding author at: Department of Surgery, School of Medicine, Complutense University of Madrid, Ramón y Cajal s.n. 28040 Madrid, Spain

E-mail addresses: maaller@med.ucm.es (M.-Á. Aller), vicente.martinez@uab.cat (V. Martínez), anarmi85@gmail.com (A. Arias), mpaznava@bio.ucm.es (M.-P. Nava), valentin.cuervasmons@uam.es (V. Cuervas-Mons), patri.vergara@uab.cat (P. Vergara), jariasp@ucm.es (J. Arias). 
mast cells in the mesenteric lymphatic complex of cholestatic rats, while increases the hepatic mucosal mast cells.

Conclusions: In cholestatic rats, Ketotifen improves liver function and ascites, and also reduces pro-inflammatory mediators in the splanchnic area. The decrease in connective tissue mast cells in the mesenteric lymphatic complex due to the administration of Ketotifen would lead to the improvement of the inflammatory splanchnic response, and consequently the abovementioned complications.

(c) 2019 Elsevier Masson SAS. All rights reserved.

\section{Introduction}

Hepatic dysfunction related to fibrosis or cirrhosis would aggravate the grade of splanchnic and systemic inflammation characteristic of portal hypertension. As a result, this would increase the incidence of complications [1,2]. It has been recognized that splanchnic mast cells are present under normal and pathological liver-related conditions in both humans and experimental animals [3-9].

It was suggested that mast cells, involved in both innate and adaptive immunity $[10,11]$, could be correlated with the evolution of experimental portal hypertension [2] and experimental hepatic chronic disease $[1,12]$. This is the reason why we have studied the hepatic-spleen-intestinal and mesenteric lymph node distribution of mucosal mast cells (MMCs) and connective tissue mast cells (CTMCs) in an experimental model of chronic liver insufficiency secondary to microsurgical obstructive cholestasis in the rat [13]. It can be accepted that this experimental model evolves in two phases. A first or "compensated" phase and a rapidly progressive "decompensated" phase, from the sixth week of postoperative evolution, resulting in the development of ascites [14].

Since Ketotifen is a mast cell stabilizer drug [15], we administered it to the obstructive cholestatic rats, either 24 hours before the intervention or during the postoperative period ( 8 weeks) to prevent decompensation of the rats, or from the sixth week of p.o. through the eighth week to treat decompensation and evaluate its effect on the potential changes in the splanchnic mast cell distribution.

\section{Materials and methods}

We used male Wistar rats, weighing between 230 and $270 \mathrm{~g}$ from the Vivarium of the Complutense University of Madrid. The experimental procedures employed in this study were performed in accordance with the Ethical Guidelines from European Community Council Directive (86/609/EEC) and published in Spanish Royal Decree 53/2013. All procedures were approved by the Complutense University Animal Welfare Committee.

\section{Experimental design}

The animals were randomly divided into six groups: shamoperated $(S ; n=15)$, rats with microsurgical cholestasis (C; $n=20$ ), early sham-operated (SK-e; $n=20$ ) and microsurgi- cal cholestatic rats (CK-e; $n=18$ ); both of these groups were administered Ketotifen early on, starting 24 hours before the operation until they were sacrificed 8 weeks post-operation; sham-operated (SK-l; $n=15$ ) and microsurgical cholestatic rats (CK-l; $n=14)$ : both of these groups were administered Ketotifen late, starting the sixth week after the operation until they were sacrificed 8 weeks post operation. In essence, early administration of Ketotifen means that the animals receive Ketotifen throughout the preoperative and postoperative periods. On the contrary, late administration of Ketotifen means that the rats only receive Ketotifen during the last two weeks of the postoperative period. All the animals were sacrificed by anaesthesia overdose at 8 weeks post operation. Body (BW), liver (LW) and spleen (SW) weights were determined.

\section{Ketotifen treatment}

For the stabilization of the mast cells, Ketotifen was added to the drinking water. The compound was dissolved in water at an initial concentration of $0.1 \mathrm{mg} / \mathrm{mL}$, allowing an estimated dosage of $10 \mathrm{mg} / \mathrm{kg}$ per day (based on a mean water consumption of $30 \mathrm{~mL} /$ day). During the treatment period, animals were housed individually. The amount of water drunk by each rat was monitored daily and the concentration of Ketotifen adjusted to ensure the desired dosage [16].

\section{Surgical procedure}

Rats were anesthetized with Ketamine Hydrochloride $(100 \mathrm{mg} / \mathrm{kg})$ and Xylazine $(12 \mathrm{mg} / \mathrm{kg})$ i.m. In S-rats, the bile duct and its lobular branches were dissected. The microsurgical cholestatic rats underwent an extrahepatic biliary tract resection using a binocular operatory microscope (Zeiss, OPMI 1-FR, Madrid, Spain), as previously described [13]. Buprenorphine $(0.05 \mathrm{mg} / \mathrm{Kg} / 8$ h s.c. $)$ was administered for analgesia the first day of the postoperative period, and antibiotic and vitamin $\mathrm{K}$ were administered during all the p.o., as previously described $[13,14]$.

\section{Portosystemic collateral circulation study method}

The splenorenal, gastroesophageal, and colorectal areas, where collateral venous circulation normally develops, were carefully studied for the presence of increased collateral veins [17]. 


\section{Portal vein pressure measurements}

Portal vein pressure (PP) was measured by inserting a fluidfilled 20-gauge needle into the splenic parenchyma [18]. Previous studies have demonstrated the excellent correlation between splenic pulp pressure and PP [19].

\section{Gross mesenteric venous vasculopathy study}

Three grades of mesenteric venous vasculopathy were considered, as previously described; grade 0: normal; grade 1: after the Pringle maneuver, and grade 2 : spontaneous $[6,20]$.

\section{Serum biochemical test}

Blood samples were drawn by puncture of the infrahepatic inferior vena cava. The serum was frozen at $-40{ }^{\circ} \mathrm{C}$ until total bilirubin (TB), alkaline phosphatase (AP), aspartate aminotransferase (AST), alanine aminotransferase (ALT), albumin and Cholesterol, Triglicerides, high density lipoprotein (HDL-C), low density lipoproteins (LDL-C), very low-density lipoproteins (VLDL) and non-esterified fatty acids (NEFAs) were assayed in an autoanalizer.

\section{TNF- $\alpha$, IL-1 $\beta$, IL-4, and IL-10 splanchnic levels}

Samples from the distal ileum $(1 \mathrm{~cm}$ from the ileo-caecal junction), the liver, the spleen, and the mesenteric lymph complex were quickly taken, frozen on dry ice, and transferred to $5 \mathrm{~mL}$ polypropylene tubes (Falcon; Becton Dickinson, Lincoln Park, NJ) containing lysis buffer $\left(4^{\circ} \mathrm{C}\right)$ at a ratio of $10 \mathrm{~mL}$ buffer $/ \mathrm{L} g$ of wet tissue. Lysis buffer was $1 \mathrm{mmol} / \mathrm{L}$ phenylmethylsulfonyl fluoride (PMSF; Sigma Chemical Company, Madrid, Spain), and $1 \mathrm{mg} / \mathrm{mL}$ pepstatin A (Sigma Chemical Company), aprotinin (Sigma Chemical Company), anti-pain (Sigma Chemical Company), and leupeptin in 13 phosphate-buffered saline solution with $\mathrm{pH} 7.2$ (Biofluids, Rockville, MD) containing $0.05 \%$ sodium azide (Sigma Chemical Company). The samples were homogenized for $30 \mathrm{~s}$ with an electrical homogenizer (Polytron; Brinkmann Instruments, Westminster, NY) at maximum speed, and immediately frozen in liquid nitrogen at $-80^{\circ} \mathrm{C}$. After thawing at $4{ }^{\circ} \mathrm{C}$, the aggregates were pelleted at $3000 \mathrm{~g}\left(4^{\circ} \mathrm{C}\right)$. Finally, the in these homogenates were assayed the quantitative levels of rat TNF- $\alpha, \mathrm{IL}-1 \beta, \mathrm{IL}-4$, and IL-10, in six animals of each group (sham-operated and cholestatic rats) using commercially available enzyme linked immunosorbent assay specific kits (BioNOVA Cientifica Ltd. Madrid, Spain).

\section{Histopathologic examinations}

Five $\mu \mathrm{m}$-thick samples of the middle liver lobe were stained with hematoxylin and eosin (H\&E) and Sirius red. An image analysis system was used to assess fibrosis grade of the hepatic tissue from the sections stained with Sirius red compared to the total area of hepatic tissue by using Leica Q Win software [21].

\section{Immunohistochemistry for rat mast cell proteinases 2 and connective mast cell counts}

Immunodetection of RMCP-II, specific marker of mucosal mast cells (MMC) in the rats, was carried out on paraformaldehyde-fixed sections using a specific rat monoclonal antibody (1:500; Moredun Animal Health, Edinburgh, UK) [22]. The connective tissue mast cells (CTMC) were detected by toluidine blue staining protocol [23]. Positively stained mast cells were counted in three to five sections of ileum per animal. Seven to ten well oriented villuscrypt units (VCU) were examined per ileum section. Mucosal $M C$ and connective tissue MC counting was normalized for the surface area of liver, lymphatic nodes and spleen, as evaluated in digital images. Cell counting was performed using an Axioskop 40 microscope [Carl Zeiss, Jena, Germany; equipped with a digital camera, Zeiss AxioCam MRm; image analysis software: Zeiss Axiovision Release 4.8.1]. Analyses of all morphological data were performed blinded to prevent observer bias [23].

\section{Statistical analysis}

The results are expressed as the mean \pm the standard deviation. Student's $t$ test for independent data or analysis of variance (ANOVA) and the Duncan test were used when appropriate for comparison of the variables between the different groups studied. The results were considered significant if $P<0.05$.

\section{Results}

The cholestatic rats displayed ascites, increased portal pressure $(P<0.001)$, mesenteric venous vasculopathy and portosystemic collateral circulation with hepatosplenomegaly $(P<0.001)$, testicular atrophy $(P<0.01)$, cholesterol $(P<0.001)$, triglycerides $(P<0.05)$ and LDL; $P<0.001)$ and VLDL; $P<0.001)$ (Table 1$)$, hyperbilirubinemia $(P<0.001)$, increased AP $(P<0.001)$, bile acids $(P<0.001)$, ASTe $(P<0.001)$ (Table 2$)$. On the contrary, hypoproteinemia $(P<0.001)$ and hypoalbuminemia $(P<0.001)$ and reduced concentration of HDL; $P<0.05$ ) (Table 3 ) were shown in these rats. Antioxidants mediators reduced in the ileum $(P<0.01)$, the liver, and in the mesenteric lymph nodes in the cholestatic rats (Table 4$)$, whereas IL-1 $\beta$ was reduced in the ileum $(P<0.05)$ and mesenteric lymph nodes, but increased in the liver $(P<0.05)$ (Table 5$).$ IL-10 increased in the ileum $(P<0.05)$; IL-4 increased in the ileum $(P<0.05)$ and in the liver; IL-13 and IL-17A increased in the ileum, but were reduced in the mesenteric lymph nodes (Table 4). Monocyte chemoattractant protein-1 (MCP-1) increased in the ileum $(P<0.05)$, and was reduced in the mesenteric lymph nodes and liver $(P<0.01)$ (Table 5$)$. Transforming growth factor beta 1 (TGF- $\beta 1$ ) increased in the ileum and liver, but was reduced in the mesenteric lymph nodes (Table 2). The cholestatic rats showed hepatic necrosis associated with epithelial biliary proliferation and fibrosis $(P<0.001)$ (Fig. 1).

The treatment with Ketotifen during the entire postoperative period of the rats with cholestasis reduced ascites, 
Table 1 Increase in body weight $(\triangle B W)$, liver weight (LW), spleen weight (SW), testes weight (TW), portal pressure (PP) and ascites in sham-operated rats (S), in microsurgical cholestatic (C) rats, in sham-operated (SK-e) and microsurgical rats (CK-e), which were early administered Ketotifen and in sham-operated (SK-l) and microsurgical rats (CK-l) that were late administered Ketotifen.

\begin{tabular}{|c|c|c|c|c|c|c|}
\hline Groups & $\Delta \mathrm{BW}(\mathrm{g})$ & LW (g) & SW (g) & TW (g) & PP (mmHg) & ASCITES (ml) \\
\hline$S n=15$ & $153^{\prime} 66 \pm 20^{\prime} 06$ & $13^{\prime} 83 \pm 2 ’ 27$ & 0’87 \pm 0 09 & $3 ’ 64 \pm 0 ’ 28$ & $8 ’ 25 \pm 2 ’ 33$ & -..--..-..-... \\
\hline$C n=20$ & $51^{\prime} 82 \pm 31^{\prime} 26^{a}$ & $26^{\prime} 01 \pm 5^{\prime} 22^{a}$ & $2^{\prime} 03 \pm 00^{\prime} 41^{a}$ & $2^{\prime} 90 \pm 0^{\prime} 55^{a}$ & $13^{\prime} 43 \pm 2^{\prime} 33^{a}$ & $6 ’ 88 \pm 5 ’ 35$ \\
\hline SK-e $n=20$ & $113^{\prime} 48 \pm 34^{\prime} 64^{a, b}$ & $12^{\prime} 13 \pm 0^{\prime} 87^{b}$ & $0^{\prime} 72 \pm 0^{\prime} 09^{b}$ & $3^{\prime} 56 \pm 0^{\prime} 16^{\text {oo }}$ & $10^{\prime} 29 \pm 2^{\prime} 12^{0 * *}$ & - \\
\hline CK-e $n=18$ & $39^{\prime} 81 \pm 24^{\prime} 65^{a, c}$ & $17^{\prime} 90 \pm 3^{\prime} 88^{c, d * *}$ & $1^{\prime} 57 \pm 0$ '39a, c, d & $2^{\prime} 23 \pm 0$ ' $85^{a, \text {, coo }}$ & $11^{\prime} 28 \pm 5^{\prime} 80^{a}$ & $3^{\prime} 71 \pm 2{ }^{\prime} 70$ \\
\hline SK-I $n=15$ & $161^{\prime} 00 \pm 39^{\prime} 28$ & $13^{\prime} 41 \pm 1 ' 37$ & $0 ’ 84 \pm 0 ’ 15$ & $3^{\prime} 78 \pm 0 ’ 37$ & $7^{\prime} 02 \pm 1 ' 83$ & -..-...-...- \\
\hline CK-I $n=14$ & $87^{\prime} 08 \pm 37^{\prime} 05++$ & $28^{\prime} 22 \pm 5^{\prime} 23^{d}$ & $2^{\prime} 11 \pm 02^{\prime}$ & $3^{\prime} 10 \pm 0^{\prime} 4^{d}$ & $15^{\prime} 04 \pm 2^{\prime} 63^{d}$ & $4^{\prime} 01 \pm$ 3’18 \\
\hline
\end{tabular}

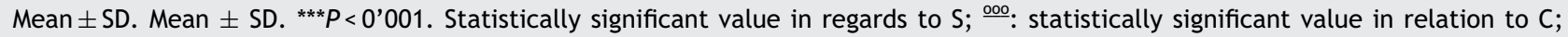

$\triangle \Delta \mathbf{\Delta}<0$ 001: statistically significant value in relation to SK-e; ${ }^{++} P<0$ '001: statistically significant value in relation to SK-l.

a $P<0$ '001. Statistically significant value in regards to $S$.

b Statistically significant value in relation to $C$.

c $P<0$ 0001: statistically significant value in relation to SK-e.

d $P<0$ 001: Statistically significant value in relation to SK-l.

body weight, the hepatosplenomegaly, total and direct bilirubin and bile acid concentrations whereas HDL levels and total protein were increased (Tables 1, 2 and 3). Ketotifen also reduced the levels of MCP-1 in the liver, TNF- $\alpha$ in the ileum and liver $(P<0.05), \mathrm{IL}-17 \mathrm{~A}$ and IL-1 $\beta$ in the ileum $(P<0.05)$ whereas concentrations of $\mathrm{IL}-4$ and $\mathrm{IL}-10$ in the liver and IL-13 in the ileum increased (Table 5).

Rats with cholestasis treated with Ketotifen starting at six weeks until they were sacrificed at eight weeks postoperation showed an increase in body weight $(P<0.01)$, and a reduction in ascites, splenomegaly $(P<0.001)$, testicular atrophy $(P<0.01)$ (Table 1$)$, collateral circulation, and intestinal mesenteric vasculopathy. Ketotifen reduced the serum index of AST/ALT $(P<0.001)$, LDH $(P<0.01)$ and creatinine $(P<0.001)$ (Table 2$)$; while $(P<0.05) \mathrm{HDL}$ and total protein levels increased (Tables 1, 2 and 3). Ketotifen also reduced $(P<0.001)$ the levels of MCP-1 in the liver, ileum, and mesenteric lymph nodes, and reduced TNF- $\alpha$ in the ileum and mesenteric lymph nodes, and IL-4, IL-13, and IL$17 \mathrm{~A}$ in the liver $(P<0.01)$ (Table 5). Lastly, Ketotifen reduced $(P<0.001)$ VEGF in all the splanchnic organs studied, while concentrations of TGF- $\beta 1$ in the liver $(P<0.05)$ and ileum (Table 1) increased.

Ketotifen administered during the entire post-operative period increased $(P<0.05)$ liver fibrosis, whereas Ketotifen administered from only week six to eight did not produce any effect (Fig. 1).

\section{Splanchnic mast cell density}

Mucosal (MMC) and connective tissue mast cells (CTMC) were determined in liver, spleen, mesenteric lymph nodes and ileum. The concentration of connective tissue mast cells and most importantly, mucosal mast cells, change in the splanchnic area in the cholestatic rats (Figs. 2-4).

CTMC in the mesenteric lymphatic complex showed an increase in relation to SKe $(P<0.05)$ and SKI $(P<0.01)$ (Fig. 2a). Ketotifen-reduced CTMC in the lymph nodes of the cholestatic rats ketotifen administered continuously (pre- and postoperatory; CKe) as in a late period of the postoperatory (CKl), did not show statistically significant dif- ferences (Fig. 2a). MMC in the mesenteric lymph nodes also increased in the cholestatic rats and both types of treatment with Ketotifen produced a reduction, although this reduction is not statistically significant in regards to the control cholestatic rats (Fig. 2a).

In the liver, no statistically significant differences of CTMC were found between the animals treated with Ketotifen and the cholestatic rats without treatment. This result is paradoxical because cholestasis in these animals caused an increase $(P<0.05)$ compared to the sham-operated animals (Fig. 2b). Similar results were found in the MMC liver. In this case, the animals with cholestasis showed an increase $(P<0.05)$ when compared to sham-operated animals and those treated with Ketotifen. Neither of the two administration methods showed statistically significant values in regards to the cholestatic rats (Fig. 2 b).

The administration of Ketotifen to the cholestatic rats did not change CTMC concentration in the ileum compared to the treated cholestatic rats (Figs. $4 a$ and 3). Furthermore, the density of MMC in the ileum did not change when Ketotifen was administered to the rats with cholestasis $(C)$, even though cholestasis is a factor associated with the increase $(P<0.05)$ of MMC in relation to the sham-operated animals (Figs. 3 and $4 a)$.

In the spleen, CTMC increased in the cholestatic rats, either those treated or not treated with Ketotifen when compared to the sham-operated rats. This CTMC increase was only statistically significant $(P<0.01)$ in the cholestatic rats that were administered Ketotifen during the late potoperative period (CKL) (Figs. 3 and $4 \mathrm{~b}$ ). In addition, the values of MMC showed an increase in the spleen of the cholestatic control rats $(C)$ and in those treated with Ketotifen (CKe and $(\mathrm{Kl})$ in regards to the sham-operated animals. However, this increase was only statistically significant $(P<0.05)$ in the control cholestatic rats (C) (Figs. 3 and 4b).

\section{Discussion}

Mast cells in rodents are divided into two types based on protease expression patterns: the connective tissue mast cells (CTMCs) and the mucosal mast cells (MMCs) [24]. MMCs, 
Table 2 Total bilirubin (TB); direct bilirubin (DB), alkaline phosphatase (AP), bile acids (BA), aspartate aminotransferase (AST), alanine aminotransferase (ALT), AST/ALT index, gamma-glutamiltranspeptidase (GGT), lacticodehidrogenase (LDH), total proteins (TP), albumin (Alb) and factor growth transforming $B 1$ in sham-operated rats (S), in microsurgical cholestatic (C) rats, in sham-operated (SK-e) and microsurgical rats (CK-e), which were early administered Ketotifen and in sham-operated (SK-l) and microsurgical rats $(\mathrm{CK}-\mathrm{l})$ that were late administered Ketotifen.

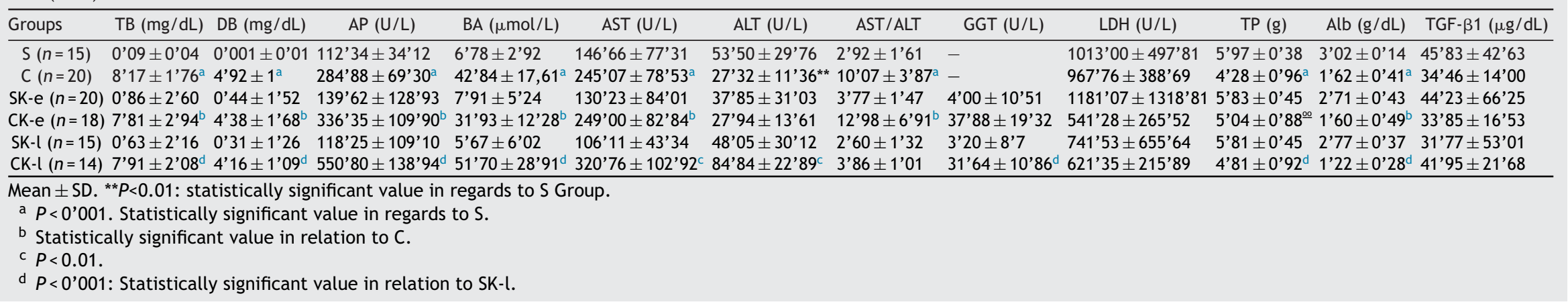


Table 3 Cholesterol, Triglicerides, high density lipoprotein (HDL-C), low density lipoproteins (LDL-C), very low density lipoproteins (VLDL) and non-esterified fatty acids (NEFAs) in sham-operated rats (S), in microsurgical cholestatic (C) rats, in sham-operated (SK-e) and microsurgical rats (CK-e), which were early administered Ketotifen and in sham-operated (SK-l) and microsurgical rats (CK-l) that were late administered Ketotifen.

\begin{tabular}{|c|c|c|c|c|c|c|}
\hline Groups & Cholesterol (mg/dl) & Triglicerides (mg/dl) & HDL-C (mmol/L) & LDL-C (mmol/L) & VLDL-C (mmol/L) & NEFAs (mmol/L) \\
\hline$S(n=15)$ & $63^{\prime} 30 \pm 10^{\prime} 19$ & $161^{\prime} 33 \pm 53^{\prime} 53$ & $0{ }^{\prime} 78 \pm 0{ }^{\prime} 11$ & $0 ’ 27 \pm 0 ’ 05$ & $0{ }^{\prime} 57 \pm 0{ }^{\prime} 22$ & $1{ }^{\prime} 39 \pm 0$ ' 88 \\
\hline$C^{\circ} \circ(n=20)$ & $143^{\prime} 31 \pm 65^{\prime} 47^{c}$ & $157^{\prime} 69 \pm 53^{\prime} 72$ & $0^{\prime} 65 \pm 0^{\prime} 16^{a}$ & $2^{\prime} 69 \pm 1^{\prime} 43^{c}$ & $0 ’ 35 \pm 0 ’ 21$ & $0^{\prime} 61 \pm 0^{\prime} 20^{b}$ \\
\hline SK-e $(n=20)$ & $70^{\prime} 30 \pm 232^{\prime} 13$ & $120^{\prime} 07 \pm 43053$ & $00^{\prime} 81 \pm 00^{\prime} 11$ & $0,52 \pm 0,85$ & $0^{\prime} 48 \pm 0{ }^{\prime} 27$ & $0,64 \pm 0,22$ \\
\hline CK-e $(n=18)$ & $158^{\prime} 30 \pm 75^{\prime} 93^{e}$ & $165^{\prime} 58 \pm 75^{\prime} 94^{d}$ & $0^{\prime} 92 \pm 02^{\prime} 23^{d}$ & $0{ }^{\prime} 48 \pm 0 ’ 27$ & $0^{\prime} 42 \pm 0,36$ & $0 ’ 49 \pm 0$ ' 17 \\
\hline SK-L $(n=15)$ & $62^{\prime} 12 \pm 26^{\prime} 72$ & $145^{\prime} 32 \pm 43^{\prime} 25$ & $0{ }^{\prime} 79 \pm 0 ' 13$ & $0 ’ 44 \pm 0 ’ 71$ & $0 ’ 38 \pm 0 ’ 16$ & $0{ }^{\prime} 65 \pm 0,32$ \\
\hline CK-I $(n=14)$ & $151^{\prime} 57 \pm 72^{\prime} 84^{f}$ & $170^{\prime} 83 \pm 93^{\prime} 68$ & $0^{\prime} 89 \pm 0{ }^{\prime} 22$ & $2^{\prime} 83 \pm 1^{\prime} 4^{f}$ & $0^{\prime} 25 \pm 0{ }^{\prime} 44$ & $0{ }^{\prime} 53 \pm 0 ’ 16$ \\
\hline
\end{tabular}

Mean \pm SD.

$P<0.01$.

a $P<0.05$.

b $P<001$

c $P<0$ ’001: Statistically significant value in regards to $S$.

d $P<0.05$.

e $P<0.001$ : Statistically significant value in relation to $C$.

f $P<0$ '001: Statistically significant value in relation to SK-I. 
Table 4 Catalase Glutation-transferase and Glutation peroxidase in the ileum, the mesenteric lymph nodes and the liver in in sham-operated rats (S), in microsurgical cholestatic (C) rats, in sham-operated (SK-e) and microsurgical rats (CK-e), which were early administered Ketotifen and in sham-operated (SK-l) and microsurgical rats (CK-l) that were late administered Ketotifen.

\begin{tabular}{|c|c|c|c|c|c|c|c|c|c|}
\hline \multirow[b]{2}{*}{ Groups } & \multicolumn{3}{|c|}{ Catalase ( $\mu \mathrm{mol} / \mathrm{mg})$} & \multicolumn{3}{|c|}{ Glutation-transferase $(\mu \mathrm{mol} / \mathrm{mg})$} & \multicolumn{3}{|c|}{ Glutation peroxidase $(\mu \mathrm{mol} / \mathrm{mg})$} \\
\hline & Ileum & Mesenteric nodes & Liver & Ileum & Mesenteric nodes & Liver & Ileum & Mesenteric nodes & Liver \\
\hline$S(n=6)$ & $1 ’ 05 \pm 0 ’ 40$ & $2 ’ 24 \pm 0 ’ 50$ & $3 ’ 18 \pm 0 ’ 08$ & $3326^{\prime} 70 \pm 1025^{\prime} 33$ & $718^{\prime} 35 \pm 135^{\prime} 08$ & $4882^{\prime} 69 \pm 474^{\prime} 24$ & $1000^{\prime} 57 \pm 136^{\prime} 63$ & $876^{\prime} 13 \pm 40^{\prime} 45$ & $5450^{\prime} 40 \pm 346^{\prime} 41$ \\
\hline$C(n=6)$ & 1’97 $\pm 0 ’ 44$ & $1 ’ 04 \pm 0 ’ 11$ & $2^{\prime} 84 \pm 0 ’ 28$ & $1925^{\prime} 40 \pm 479^{\prime} 40^{a}$ & $321^{\prime} 49 \pm 16^{\prime} 54^{a}$ & $1681^{\prime} 90 \pm 144^{\prime} 69^{b}$ & $799^{\prime} 72 \pm 128^{\prime} 67$ & $962 ’ 91 \pm$ 5’50 & $2750^{\prime} 67 \pm 126^{\prime} 49$ \\
\hline SK-e $(n=6)$ & $2^{\prime} 23 \pm 0 ’ 53$ & $3 ’ 73 \pm 0 ’ 05$ & $3^{\prime} 60 \pm 0 ’ 30$ & $2823^{\prime} 05 \pm 479^{\prime} 48$ & $1137^{\prime} 17 \pm 4^{\prime} 59$ & $5459 ’ 24 \pm 349 ’ 26$ & $1062 ’ 91 \pm 100 ’ 15$ & $972 ’ 92 \pm 55^{\prime} 87$ & $7309^{\prime} 65 \pm 308^{\prime} 37$ \\
\hline CK-e $(n=6)$ & $1 ’ 34 \pm 0 ’ 26$ & $0^{\prime} 97 \pm 0^{\prime} 06^{d}$ & $2^{\prime} 56 \pm 00^{\prime} 20^{\prime}$ & $2306^{\prime} 16 \pm 213^{\prime} 07$ & $318^{\prime} 09 \pm 7^{\prime} 89^{d}$ & $1622^{\prime} 26 \pm 80^{\prime} 87^{e}$ & $597^{\prime} 66 \pm 63^{\prime} 27^{d}$ & $1085^{\prime} 72 \pm 67^{\prime} 32$ & $2759^{\prime} 15 \pm 309^{\prime} 96^{e}$ \\
\hline SK-I $(n=6)$ & $2^{\prime} 84 \pm 0{ }^{\prime} 81$ & $2^{\prime} 67 \pm 0 ’ 57$ & $3^{\prime} 40 \pm 00^{\prime} 86$ & $2584^{\prime} 49 \pm 982^{\prime} 12$ & $577^{\prime} 33 \pm 296 ’ 83$ & $6429^{\prime} 42 \pm 858^{\prime} 52$ & $1130^{\prime} 83 \pm 239^{\prime} 25$ & $987^{\prime} 90 \pm 342 ’ 24$ & $2258^{\prime} 26 \pm 1652^{\prime} 68$ \\
\hline CK-I $(n=6)$ & $0^{\prime} 60 \pm 0^{\prime} 43^{f}$ & 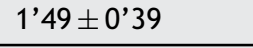 & $3^{\prime} 40 \pm 0$ '38 & $1921^{\prime} 82 \pm 519 ' 61$ & $268 ' 39$ & $1439^{\prime} 36 \pm 376^{\prime} 84^{\mathrm{e}}$ & $865^{\prime} 95 \pm 474^{\prime} 97^{d}$ & $529^{\prime} 73 \pm 265^{\prime} 47^{c}$ & $2534^{\prime} 17 \pm 178^{\prime} 26$ \\
\hline \multicolumn{10}{|l|}{$\begin{array}{c}\text { Mean } \pm \text { SD. } \\
\text { a } P<001 \text {. }\end{array}$} \\
\hline
\end{tabular}


Table 5 Tumoral necrosis Factor alpha (TNF- $\alpha$ ), Interleukin-1ß (IL-1ß), Monocyte chemoattractant protein-1 (MCP-1), Interleukin-13 (IL-13), Interleukin-17A (IL-17A), Interleukin 4 (IL-4) and Interleukin 10 (IL-10) in the ileum, the mesenteric lymph nodes and the liver in in sham-operated rats (S), in microsurgical cholestatic (C) rats, in sham-operated (SK-e) and microsurgical rats (CK-e), which were early administered Ketotifen and in sham-operated (SK-l) and microsurgical rats (CK-l) that were late administered Ketotifen.

\begin{tabular}{|c|c|c|c|c|c|c|c|c|c|}
\hline \multirow[t]{2}{*}{ Groups } & \multicolumn{3}{|c|}{ TNF- $\alpha$ (pg/100 mg) } & \multicolumn{3}{|c|}{ IL-1 $\beta$ (pg/100 mg) } & \multicolumn{3}{|c|}{ MPC-1 } \\
\hline & Ileum & Mesenteric nodes & Liver & Ileum & Mesenteric nodes & Liver & Ileum & Mesenteric nodes & Liver \\
\hline$S(n=6)$ & $130 ’ 24 \pm 37^{\prime} 76$ & $129^{\prime} 83 \pm 22^{\prime} 48$ & $505^{\prime} 56 \pm 65^{\prime} 19$ & $266^{\prime} 02 \pm 42^{\prime} 53$ & $431^{\prime} 85 \pm 110^{\prime} 88$ & $173^{\prime} 20 \pm 30^{\prime} 16$ & 7’30 $\pm 2 ’ 59$ & $29^{\prime} 65 \pm 2 ’ 22$ & $9^{\prime} 75 \pm 1^{\prime} 01$ \\
\hline$C(n=6)$ & $192^{\prime} 27 \pm 161^{\prime} 47$ & $141^{\prime} 34 \pm 59^{\prime} 21$ & $352^{\prime} 00 \pm 255^{\prime} 13$ & $150^{\prime} 87 \pm 44^{\prime} 57^{*}$ & $436^{\prime} 10 \pm 63^{\prime} 39$ & $249^{\prime} 71 \pm 96^{\prime} 64$ & $17^{\prime} 22 \pm 6^{\prime} 24^{*}$ & $16^{\prime} 23 \pm 4^{\prime} 18$ & $31^{\prime} 83 \pm 16^{\prime} 78$ \\
\hline SK-e $(n=6)$ & $40^{\prime} 14 \pm 35^{\prime} 60$ & $138^{\prime} 29 \pm 32^{\prime} 01$ & $268^{\prime} 82 \pm 77^{\prime} 06$ & $154^{\prime} 82 \pm 86^{\prime} 66$ & $502^{\prime} 68 \pm 79^{\prime} 99$ & $103^{\prime} 73 \pm 71^{\prime} 07$ & $6^{\prime} 56 \pm 2^{\prime} 80$ & $184^{\prime} 63 \pm 26^{\prime} 66$ & $5^{\prime} 70 \pm 0 ’ 95$ \\
\hline CK-e $(n=6)$ & $36^{\prime} 57 \pm 10^{\prime} 78$ & $69^{\prime} 84 \pm 17^{\prime} 01^{\circ 0}$ & $125^{\prime} 99 \pm 76^{\prime} 08^{\circ}$ & $170^{\prime} 00 \pm 20^{\prime} 53$ & $266^{\prime} 65 \pm 81^{\prime} 12$ & $204^{\prime} 58 \pm 104^{\prime} 51^{\circ}$ & - $26 ’ 93 \pm 19^{\prime} 39$ & $94^{\prime} 12 \pm 13^{\prime} 06^{\circ}$ & $26^{\prime} 93 \pm 8^{\prime} 56^{\circ 0}$ \\
\hline SK-I $(n=6)$ & $85^{\prime} 97 \pm 20^{\prime} 46$ & $157^{\prime} 66 \pm 51^{\prime} 13$ & $2256^{\prime} 32 \pm 157^{\prime} 36$ & $431^{\prime} 66 \pm 115^{\prime} 12$ & $483^{\prime} 82 \pm 194^{\prime} 92^{\circ-0}$ & $884^{\prime} 76 \pm 54^{\prime} 86$ & $72^{\prime} 69 \pm 30^{\prime} 07$ & $44^{\prime} 07 \pm 19^{\prime} 83$ & $235^{\prime} 24 \pm 40^{\prime} 10$ \\
\hline CK-l $(n=6)$ & $299^{\prime} 64 \pm 32^{\prime} 59^{++}$ & $+\quad 76^{\prime} 05 \pm 13^{\prime} 34^{+++}$ & $852^{\prime} 35 \pm 505^{\prime} 56^{++}$ & $140^{\prime} 29 \pm 17^{\prime} 35^{+}$ & $631^{\prime} 04 \pm 194^{\prime} 60$ & $495^{\prime} 26 \pm 153^{\prime} 06^{+}$ & $+\quad 59 \prime 10 \pm 34^{\prime} 16$ & $110^{\prime} 66 \pm 95^{\prime} 03^{+}$ & $276^{\prime} 61 \pm 150^{\prime} 23$ \\
\hline \multirow[t]{2}{*}{ Groups } & \multicolumn{3}{|c|}{ IL-13 (pg/100 mg) } & \multicolumn{3}{|c|}{ IL-17A (pg/100 mg) } & \multicolumn{3}{|c|}{ IL-4 (pg/100 mL) } \\
\hline & Ileum & Mesenteric nodes & Liver & Ileum & Mesenteric nodes & Liver & Ileum & Mesenteric nodes & Liver \\
\hline$S(n=6)$ & $12^{\prime} 16 \pm 2^{\prime} 88$ & $44^{\prime} 62 \pm 22^{\prime} 61$ & $20^{\prime} 79 \pm 4^{\prime} 96$ & $15^{\prime} 29 \pm 4^{\prime} 73$ & $5^{\prime} 72 \pm 30^{\prime} 31$ & $33^{\prime} 10 \pm 8^{\prime} 77$ & $15^{\prime} 87 \pm 7^{\prime} 36$ & $40^{\prime} 77 \pm 0 ’ 86$ & $53^{\prime} 28 \pm 7^{\prime} 56$ \\
\hline$C(n=6)$ & $18^{\prime} 71 \pm 8^{\prime} 88$ & $24^{\prime} 78 \pm 10^{\prime} 19$ & $24^{\prime} 20 \pm 11^{\prime} 25$ & $27^{\prime} 83 \pm 16^{\prime} 83$ & $7^{\prime} 91 \pm 13^{\prime} 47$ & $40^{\prime} 67 \pm 21^{\prime} 68$ & $28^{\prime} 05 \pm 13^{\prime} 02^{*}$ & $40^{\prime} 55 \pm 12^{\prime} 39$ & $47^{\prime} 58 \pm 15^{\prime} 03$ \\
\hline SK-e $(n=6)$ & $8^{\prime} 02 \pm 1 ' 53$ & $51^{\prime} 23 \pm 21^{\prime} 13$ & $27^{\prime} 14 \pm 7^{\prime} 45$ & $12^{\prime} 73 \pm 5^{\prime} 77$ & $0^{\prime} 22 \pm 28{ }^{\prime} 35$ & $58^{\prime} 03 \pm 12^{\prime} 01$ & $13^{\prime} 82 \pm 6{ }^{\prime} 29$ & $42^{\prime} 89 \pm 1^{\prime} 02$ & $18^{\prime} 15 \pm 8^{\prime} 20$ \\
\hline CK-e $(n=6)$ & $15^{\prime} 09 \pm 3^{\prime} 35^{\circ}$ & $87^{\prime} 63 \pm 4^{\prime} 65^{\circ}$ & $21^{\prime} 97 \pm 7^{\prime} 91$ & $29^{\prime} 52 \pm 6^{\prime} 78^{\circ} \quad 99$ & $9^{\prime} 10 \pm 17^{\prime} 88^{\circ}$ & $78^{\prime} 11 \pm 20^{\prime} 73^{\circ}$ & $28^{\prime} 60 \pm 9^{\prime} 65^{\circ}$ & $76^{\prime} 56 \pm 3^{\prime} 23^{\circ 00}$ & $60^{\prime} 81 \pm 5^{\prime} 42^{2000}$ \\
\hline SK-I $(n=6)$ & $20^{\prime} 19 \pm 7^{\prime} 48$ & $40^{\prime} 41 \pm 24^{\prime} 85$ & $110^{\prime} 26 \pm 28^{\prime} 93$ & $25^{\prime} 56 \pm 9^{\prime} 87$ & $0^{\prime} 69 \pm 42{ }^{\prime} 16$ & $174^{\prime} 14 \pm 28^{\prime} 28$ & $J^{\prime} 12 \pm 0{ }^{\prime} 01$ & $157^{\prime} 66 \pm 51^{\prime} 13$ & $277^{\prime} 77 \pm 11^{\prime} 42$ \\
\hline CK-I $(n=6)$ & $35^{\prime} 49 \pm 23^{\prime} 09$ & $26^{\prime} 19 \pm 46^{\prime} 97$ & $37^{\prime} 38 \pm 20^{\prime} 38^{+++}$ & $40^{\prime} 78 \pm 28^{\prime} 23 \quad 78$ & '8'84 4 77’08 & $53^{\prime} 44 \pm 26^{\prime} 06^{++}$ & $15^{\prime} 22 \pm 18^{\prime} 59^{++}$ & $76^{\prime} 05 \pm 19^{\prime} 34^{+}$ & $97^{\prime} 22 \pm 25^{\prime} 95^{++}$ \\
\hline
\end{tabular}

Mean \pm SD. * $P<005$; Statistically significant value in regards to $S,{ }^{\circ} P<0.05 ;{ }^{\circ} \circ P<0.01 ;{ }^{000} P<0.001$ : Statistically significant value in relation to $C$; ${ }^{+} P<0.05 ;++P<0.01 ;+++P<0.001$ : Statistically significant value in relation to SK-l. 


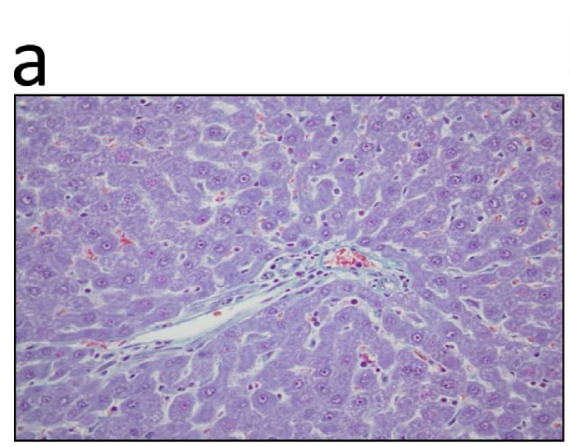

b
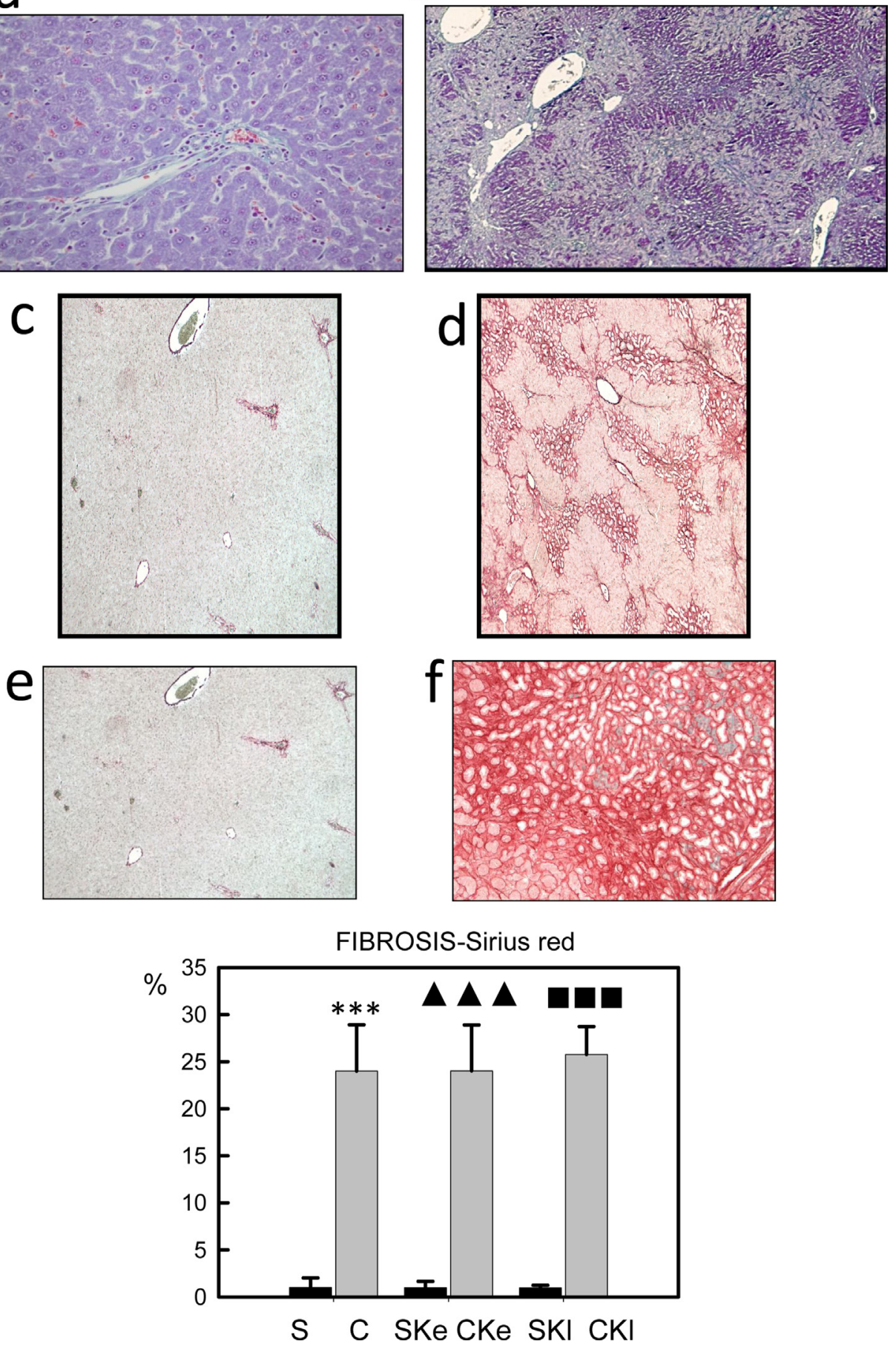

Figure 1 a: Microscopical Liver image in a sham-operated rat (S; H\&E); b: in one microsurgical cholestatic (C; H\&E) rat, in which a severe fibrosis and biliary proliferation is shown (H\&E); c: in a sham-operated (SK-e) (Sirius red stain) and d. one microsurgical rat (CK-e) (Sirius red stain), which were both early administered Ketotifen (Sirius red stain); d: in one sham-operated (SK-l) rat and e: in one microsurgical cholestatic rats (CK-l) that were both late administered Ketotifen(Sirius red stain) and $\mathrm{f}$ ) liver areas occupied by fibrosis, determined by spectrophotometry after Sirius red stain in the above mentioned groups. Mean $\pm D E$; ${ }^{* * *} P<0.001$ : statistically significant value in regards to $S$ group; $\boldsymbol{\Delta} \mathbf{\Delta} \boldsymbol{\Delta} P<0.001$ : statistically significant value in regards to SK-e group; $\square P<0.001$ : statistically significant value in regards to SK-l group. 

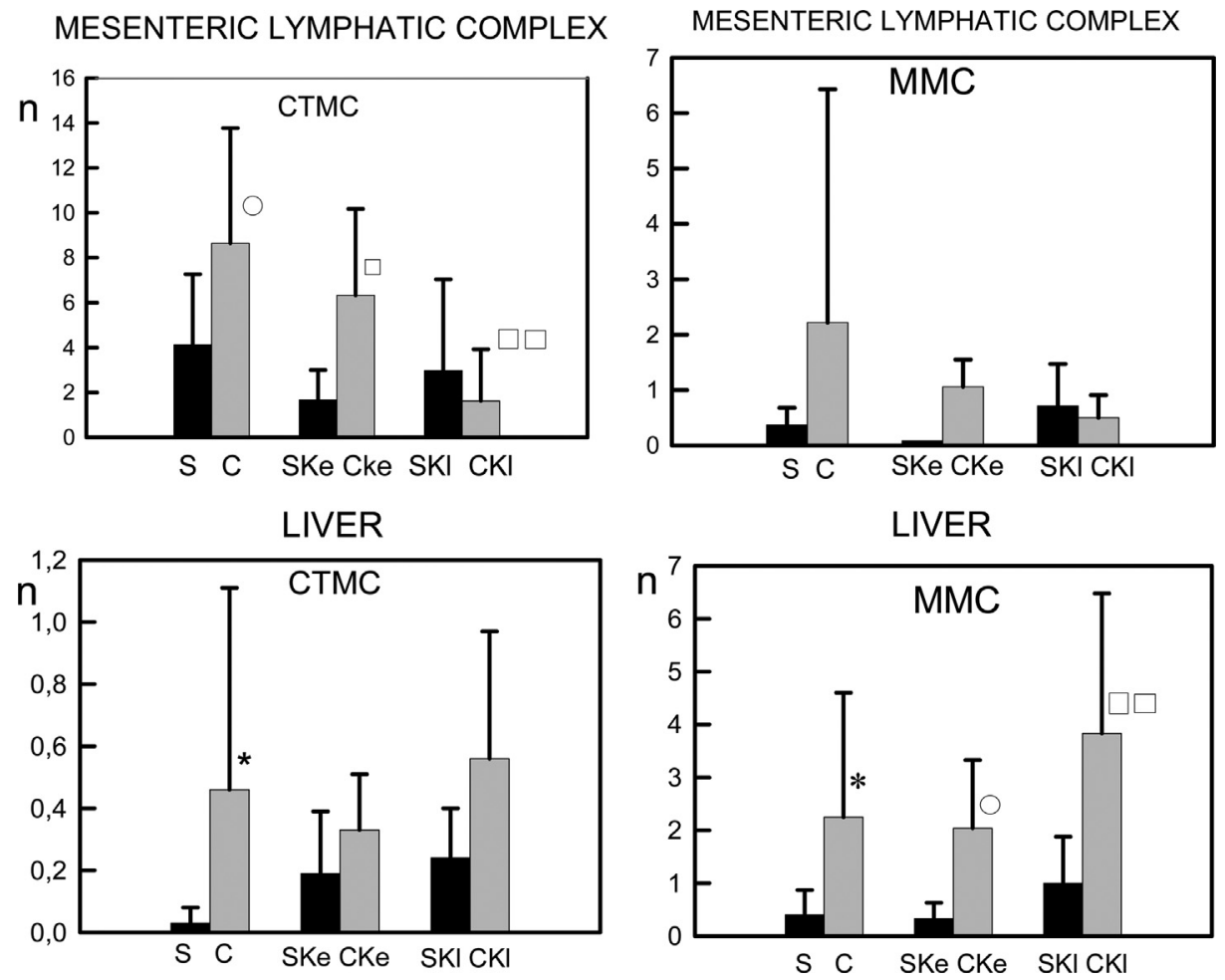

Figure 2 Mucosal mast cells (MMC) and connective tissue mast cells (CTMC) In the mesenteric lymphatic complex (a) and in the liver (b) in sham-operated (SK-e) and in microsurgical cholestatic rats (CK-e), which were both early administered Ketotifen and in sham-operated (SK-l) rats and in microsurgical cholestatic rats (CK-l) that were both late administered Ketotifen. Mean \pm DE; ${ }^{*} P<0.05$ : statistically significant value in regards to $S$ group; $O P<0.05$ : statistically significant value in regards to SK-e group; $\square P<0.05 ; \square \square P<0.01$ : statistically significant value in regards to SK-l group.

a
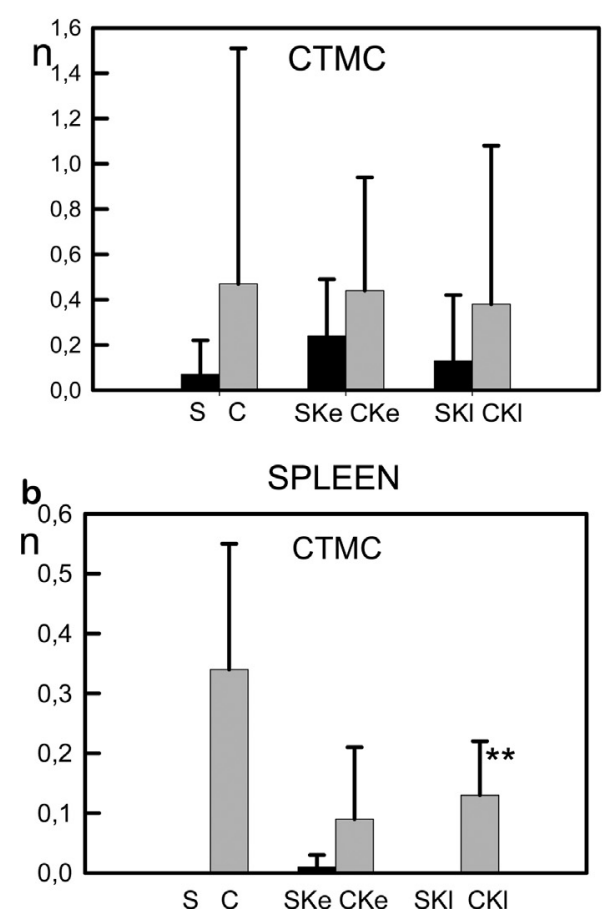

ILEUM
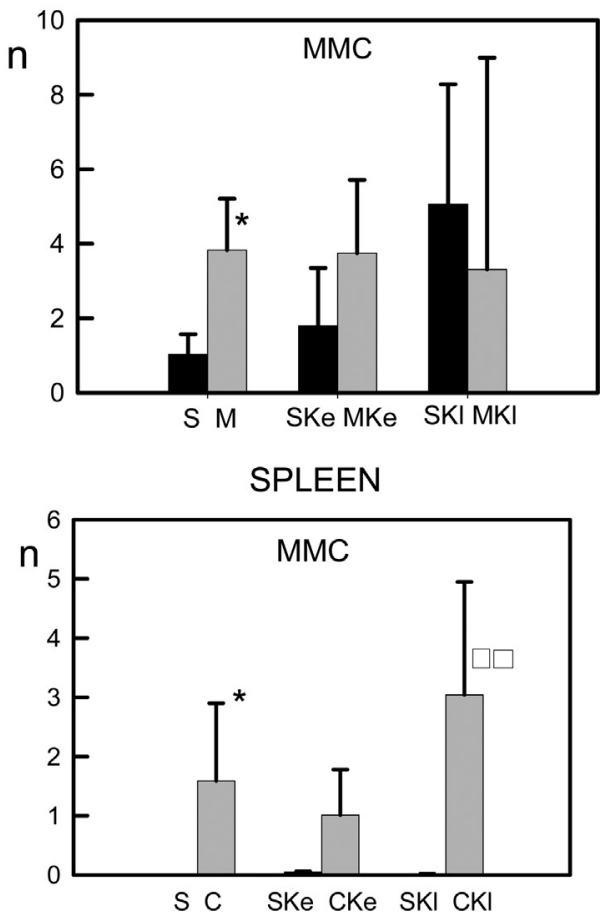

Figure 3 Connective Tissue mast cells [CTMC] [A] were identified after stained with Toluidin blue as granulated violet/blue cells in the lymphatic nodes of cholestatic rats and [B] in and in microsurgical cholestatic rats (CK-e), which were early administered Ketotifen. Mucosal mast cells [C] were identified as rMCP-II green immunopositive cells in the liver of cholestatic rats, and [D] in the liver of microsurgical cholestatic rats (CK-e), which were early administered Ketotifen. 
located in mucosal compartments, express chymase (mouse mast cell proteases mMCP-1and MMCP-2). Connective tissue type mast cells, located in the skin and blood vessel, express chymase, tryptase and carboxypeptidase A [25]. The increase of both populations of MCs in the liver and of MMC in the small bowel of rats with obstructive cholestasis could indicate that they are involved in the impairments developed by these two organs.

Therefore, in this experimental model, it could be considered that two overlapping pathological conditions participate: hepatic insufficiency caused by cholestasis, which in produces fibrosis and portal hypertension. Therefore, Ketotifen administration would act differentely on one or the other pathological conditions.

In the liver, the inflammatory response against cholestasis is considered a wound-like inflammatory liver response [26], i.e. portal fibrosis and proliferation of the biliary epithelial cells [27], and could be mediated by mast cells. It is well known that mast cells are involved in the fibrosis related wound-healing process [28-30]. Moreover, there is a positive correlation between mast cell number/activity and scar formation mediated by fibroblasts [28,30]. Although data indicates that mast cells and their mediators are beneficial [31-33] in the different phases of wound healing, they can also have detrimental roles, especially when CTMC are chronically activated [29]. There is evidence that mast cells are involved in various hepatobiliary disorders, such as chronic liver diseases and biliary/cholestatic diseases $[34,35]$. This suggests that they are at least involved in inflammation and periportal fibrosis [12,35-37]. In addition, mast cells produce cytokines and growth factors that can promote excessive biliary epithelial cells proliferation [29]. This would therefore explain why a reduction of fibrosis is produced in the cholestatic rats after Ketotifen is administered. Since the number of mast cells in the Ketotifen-treated cholestatic rats and those not treated with Ketotifen does not differ, the reduction of fibrosis could be attributed to extra-hepatic factors. Therefore, the existence of porto-systemic collateral circulation would reduce the effectiveness of this drug since it was administered orally. Moreover, oral administration during states of portal hypertension would not be the most appropriate use of this drug to successfully reach the hepatic circulation and stabilize the mast cells, thus reducing its profibrogenic activity. Furthermore, in cholestasis, the hepatic accumulation of bilirubin, a potent anti-oxidant and anti-inflammatory substance $[14,26]$, could be a cause of fibrogenisis limitation. Consequently, we must remember that the effects of Ketotifen when it reaches the liver by systemic recirculation through the hepatic artery modifies the mast cell phenotype and, therefore achieves an anti-fibrogenic action without changing the amount of mast cells.

On the contrary, the effectiveness of Ketotifen administered orally would be greater for the intestine suffering portal hypertension. The increase of portal pressure also spreads to the post-capillar venules of the splanchnic venous system and can produce gastrointestinal impairments by mechanotransduction [38]. In particular, the excessive mechanical energy acting over the gastrointestinal venous vascular wall would not only affect the endothelium through mechanotransduction, but also those cells that are in its neightborhood, like the gastrointestinal mast cells [39]. Thus, the increase of mast cells in cholestatic rats with portal hypertension could be related to the mechanotransductor stimulus caused by portal hypertension. If so, the intestinal inflammatory activation of the mast cells would favor the production and release of proinflammatory mediators through an array of mechanisms, such as degranulation, exosomes/ extracellular vesicles, tunneling nanotubes, and extracellular trap formation [40]. The mast cells then turn into mediators of the portal hypertension pathology affecting the organism. The excess of intestinal MMC mast cells, through the production and release of angiogenic (VEGF) and other growth factors, such as basic fibroblastic growth factor (FGF2) $[3,11]$, in the cholestatic rats, could be related to the development of hypertensive portal intestinal vasculopathy. Thus, the impact of the portal hypertension mediated by mast cells would induce angiogenesis in the gastrointestinal tract [38].

Hence, it could be considered that the mast cells in the extrahepatic cholestatic rat collaborate in the proliferation phase of splanchnic wound healing and in the distribution of the two main components that form granulation tissue throughout the portal system. In other words, fibrogenesis in the liver with increased deposition of collagen. In this experimental model of acute-on-chronic liver failure, the mast cells would therefore participate in the inflammatory splanchnic response involved in the wound healing gut-liver response.

Likewise, due to the close relationship that the mast cells have with neurons, they would produce neurogenic inflammation and portal hypertensive encephalopathy [39]. The mediators released by the mast cells that bypass the liver and reach the systemic circulation through the portosystemic collateral vessels would also take part $[17,26]$ in the development of this type of encephalopathy [39].

It is known that after antigen stimulus, mast cells migrate to secondary lymphoid organs and can present antigens to the naïve $T$ cells contributing to the adaptive immune response $[41,42]$. Thus, the increased density of the CTMC in the mesenteric lymph nodes found in longterm cholestatic rats could be the result of their migration from the hepatic-intestinal inflamed tissues. So, CTMC could effectively induce an adaptive immune response and could modulate the development of the splanchnic inflammatory response in rats with biliary fibrosis and hypertensive portal intestinal vasculopathy. The tendency for mast cells to decrease in the mesenteric lymph nodes in the cholestatic rats treated with Ketotifen (Fig. 4a) would suggest their reduced ability to activate the acquired immunity. If so, the administration of Ketotifen, which reduces the number of mast cells in the mesenteric lymph nodes, would lessen the intestinal inflammatory activity mediated by the acquired immunity and, therefore would lower the intestinal levels of proinflammatory mediators, such as TNF- $\alpha$, IL-17 e IL-1 $\beta$ (Table 5).

In addition, the mast cells, given that they release mediators that produce vasodilation and vascular permeability, including histamine and serotonin [10], would therefore participate in the acute-on-chronic inflammatory splanchnic response causing ascites [43]. However, it cannot be ruled out that one of the mechanisms producing ascites 
a
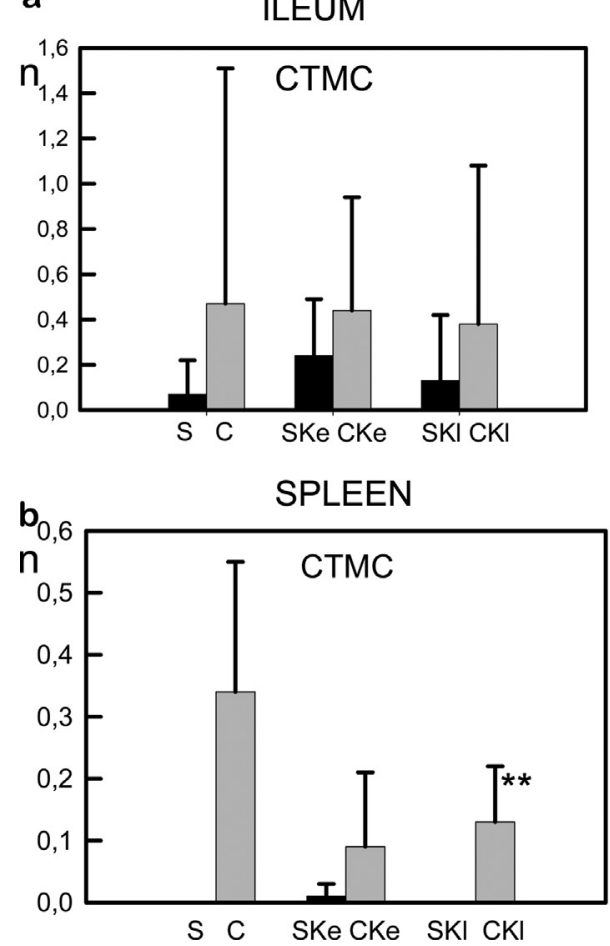
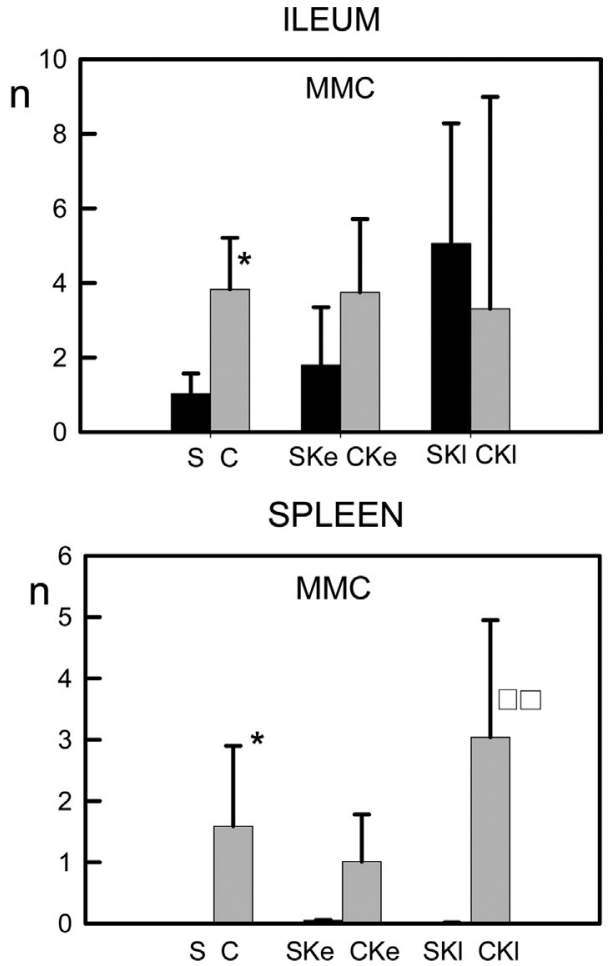

Figure 4 a Mucosal mast cells (MMC) and connective tissue mast cells (CTMC) in the ileum (a) and in the spleen (b) in shamoperated (SK-e) and in microsurgical cholestatic rats (CK-e), which were both early administered Ketotifen and in sham-operated (SK-l) rats and in microsurgical cholestatic rats (CK-l) that were both late administered Ketotifen. Mean $\pm D E ;{ }^{*} P<0.05$; ** statistically significant value in regards to S group; $\square \square P<0.01$ : statistically significant value in regards to SK-I group.

in rats with hepatic insufficiency and portal hypertension is splanchnic inflammation related to the mast cell immunity activation in the mesenteric lymph nodes. Therefore, the abovementioned tendency of CTMC reduction in the mesenteric lymph nodes in the cholestatic rats treated with Ketotifen would be associated with ascitic volume reduction. Likewise, the acquired immunity developed by mast cells in the mesenteric lymph nodes could participate in hepatic inflammation and, in this case, in reducing fibrogenesis associated with the improvement of the hepatic function after the treatment with Ketotifen.

The increase of mast cells after transplantation has also been involved in conditioning dendritic cells to mediate allograft tolerance [44]. In addition, mast cells can also regulate $\mathrm{T}$-cell responses and regulatory $\mathrm{T}$-cell (Treg) functionality after transplantation. Consequently, it has been suggested that they could regulate the balance between tolerance and inflammation $[45,46]$. The plasticity of mast cells suggests that the phenotype of these cells likely changes over time. If so, MMC located in epithelium organs (liver and ileum) could transform in CTMC when they are in the spleen or the mesenteric lymphatic complex. This could allow mast cells to change their function as a wound heals and could help explain their functional diversity during repair $[28,29,47]$. Moreover, mast cells, a source of anti-inflammatory/immunosuppressive mediators, could also mediate inflammation resolution, an active process necessary for effectively terminating the inflammatory response $[29,48]$.
Consequently, the continued administration of Ketotifen reduces CTMC in the mesenteric lymph node complex, and is associated with improved liver function and a reduction of ascites volume. These results suggest the possible involvement of the CTMC located in the secondary lymphoid splanchnic organs, in the splanchnic inflammatory pathology related to obstructive jaundice. Consequently, the increased accumulation of CTMC in the splanchnic lymph nodes appears to play a pivotal role in portal hypertension as well as in their pathological consequences, including liver fibrosis, intestinal angiogenesis and ascites.

Lastly, Ketotifen as a mast cell membrane stabilizer and histamine release inhibitor would cause an important environmental change in the splanchnic area characteristic of the mast cell pattern switch. Therefore, it must be kept in mind that after the administration of Ketotifen, the mast cell phenotype changes, which could favor the antiinflammatory and proresolutive role of MMC. It is well known that changes in mast cell phenotype can take place during virtually all stages of mast cell existence, which demonstrates their extreme sensibility to environmental changes [48].

In conclusion, our study suggests a relevant role of the CTMC in the secondary lymphoid splanchnic organs in inducing acute-on-chronic liver failure found in patients and animals with well compensated cirrhosis who rapidly deteriorate after a precipitating event [49], as well as the resulting potential benefit of the constant treatment with Ketotifen Box 1. 
Box 1: Mast cells and experimental cholestatic liver disease.

Mast cells are a type of inflammatory cells involved in the splanchnic area, including the liver and the gastrointestinal tract in chronic liver diseases.

Mast cells are involved in the splanchnic inflammatory response related to the liver diseases through an acquired immune response that is reduced by Ketotifen administration.

The modulation of the mast cell inflammatory functions in chronic liver diseases would reduce the severity of their associated complications, including hepatic fibrosis and ascites

\section{Ethical approval}

The experimental procedures employed in this study were in accordance with the Ethical Guidelines from European Community Council Directive (86/609/EEC) and published in Spanish Royal Decree 53/2013. All procedures were approved by the Complutense University Animal Welfare Committee.

\section{Funding}

This study was supported with a grant from the Mutua Madrileña Automovilista, Ref. No. AP6977/2009.

\section{Authors' contribution}

M.A.A., J.A. and P.V. designed the study and wrote the manuscript, A.A., V.M. and VC.M. analyzed and interpreted the data. All authors gave approval of the submitted version of the manuscript.

\section{Disclosure of interest}

The authors declare that they have no competing interest.

\section{References}

[1] Aller MA, Arias JL, Cruz A, Arias J. Inflammation: a way to understanding the evolution of portal hypertension. Theor Biol Med Model 2007;4:44.

[2] Aller MA, Arias JL, Arias J. The mast cell integrates the splanchnic and systemic inflammatory response in portal hypertension. J Transl Med 2007;5:44, http://dx.doi.org/10.1186/1742-4682-4-44.

[3] Diez-Arias JA, Aller MA, Palma MD, Arias JL, Muñiz E, Sánchez $M$, Arias J. Increased duodenal mucosa infiltration by mast cells in rats with portal hypertension. Dig Surg 2001;18:34-40, http://dx.doi.org/10.1159/000050094.

[4] Grizzi F, Franceschini B, Barbieri B, Gagliano N, Arosio B, Chiriva-Internati M, Annoni G, Dioguardi N. Mast cell density: a quantitative index of acute liver inflammation. Anal Quant Cytol Histol 2002;24:63-9 [PMID: 12026051].

[5] Grizzi F, Franceschini B, Gagliano N, Moscheni C, Annoni G, Vergani C, Hermonat PL, Chiriva-Internati M, Dioguardi $\mathrm{N}$. Mast cell density, hepatic stellate cell activation and
TGF-beta1 transcripts in the aging Sprague-Dawley rat during early acute liver injury. Toxicol Pathol 2003;31:173-8, http://dx.doi.org/10.1080/01926230390183643.

[6] Prieto I, Aller MA, Santamaría L, Nava MP, Madero R, Pérez-Robledo JP, Arias J. Prehepatic portal hypertension produces increased mast cell density in the small bowel and in mesenteric lymph nodes in the rat. J Gastroenterol Hepatol 2005;20:1025-31, http://dx.doi.org/10.1111/j.1440-1746.2005.03831.x.

[7] Franceschini B, Ceva-Grimaldi G, Russo C, Dioguardi N, Grizzi F. The complex functions of mast cells in chronic human liver diseases. Dig Dis Sci 2006;51:2248-56, http://dx.doi.org/10.1007/s10620-006-9082-8.

[8] Moquillaza LM, Aller MA, Nava MP, Santamaría L, Vergara $\mathrm{P}$, Arias J. Partial hepatectomy, partial portal vein stenosis and mesenteric lymphadenectomy increase splanchnic mast cell infiltration in the rat. Acta Histochem 2010;112:372-82, http://dx.doi.org/10.1016/j.acthis.2009.03.002.

[9] Frizzi F, Di Caro G, Laghi L, Hermonat P, Mazzola P, Nguyen DD, Radhi S, Figueroa JA, Cobos E, Annoni G, Chiriva-Internati M. Mast cells and the liver aging process. Immun Ageing 2013;10:9, http://dx.doi.org/10.1186/1742-4933-10-9.

[10] Galli SJ, Nakae S, Tsai M. Mast cells in the development of adaptive immune responses. Nat Immunol 2005;6:135-42, http://dx.doi.org/10.1038/ni1158.

[11] Wernersson S, Pejler G. Mast cell secretory granules: armed for battle. Nat Rev Immunol 2014;14:478-94, http://dx.doi.org/10.1038/nri3690.

[12] Aller MA, Ortega L, Sánchez-Patán F, Anchuelo R, SánchezPatán F, Anchuelo R, Cruz A, Losada M, Arias J. Microsurgical extrahepatic cholestasis in the rat: a histopathological liver study. The Open Pathol J 2008;2:71-7.

[13] Aller MA, Lorente L, Alonso S, Arias J. A model of cholestasis in the rat, using a microsurgical technique. Scand J Gastroenterol 1993;28:10-4 [PMID: 8430270].

[14] Aller MA, Prieto I, Cruz A, Losada M, Arias JI, García-Domínguez J, Argudo S, Arias JL, Arias J Extrahepatic Cholestasis. Aller MA, Arias J, Microsurgery in Liver Research. Bentham Scientific; 2009; 137-156.

[15] Sastre E, Caracuel L, Xavier FE, Balfagón G, Blanco-Rivero J. Opposite effect of mast cell stabilizers ketotifen and tranilast on the vasoconstrictor response to electrical field stimulation in rat mesenteric artery. PLoS One 2013;8:e73232., http://dx.doi.org/10.1371/journal.pone.0073232.

[16] Fernández-Blanco JA, Hollenberg MD, Martínez V, Vergara P. PAR-2-mediated control of barrier function and motility differs between early and late phases of postinfectious gut dysfunction in the rat. Am J Physiol Gastrointest Liver Physiol 2013;304:G390-400, http://dx.doi.org/10.1152/ajpgi.00387.2012.

[17] Dieguez B, Aller MA, Nava MP, Palma MD, Arias JL, López $\mathrm{L}$, Arias J. Chronic portal hypertension in the rat by triple portal stenosing ligation. J Invest Surg 2002;15:329-36, http://dx.doi.org/10.1080/08941930290086146.

[18] Castaneda B, Dubernardi-Venon W, Bandi JC, Andreu V, Pérez-del-Pulgar S, Moitinho E, Pizcueta P, Bosch J. The role of portal pressure in the severity of bleeding in portal hypertensive rats. Hepatology 2000;31:581-6, http://dx.doi.org/10.1002/hep.510310306.

[19] Kravetz D, Sikuler E, Groszmann R. Splanchnic and systemic hemodynamics in portal hypertensive rats during hemorrhage and blood volume restitution. Gastroenterology 1986;90:1232-40 [PMID: 3956942].

[20] Palma MD, Aller MA, Vara E, Nava MP, Garcia C, Arias-Diaz J, Balibrea JL, Arias J. Portal hypertension produces an evolutive hepato-intestinal pro- and antiinflammatory response in the rat. Cytokine 2005;31:213-26, http://dx.doi.org/10.1016/j.cyto.2005.04.008. 
[21] Standish RA, Cholongitas E, Dhillon A, Burroughs AK, Dhillon AP. An appraisal of the histopathological assessment of liver fibrosis. Gut 2006;55:569-78, http://dx.doi.org/10.1136/gut.2005.084475.

[22] Sanchez-Patan F, Anchuelo R, Corcuera MT, Casado I, GómezAguado F, Aller MA, Cruz A, Alonso MJ, Arias J. Biliary fibrosis in microsurgical extrahepatic cholestasis in the rat. Microsurgery 2008;28:361-6, http://dx.doi.org/10.1002/micr.20495.

[23] Serna H, Porras $M$, Vergara P. Mast cell stabilizer ketotifen [4-(1-methyl-4-piperidylidene)-4h-benzo $[4,5]$ cyclohepta [1,2-b] thiophen-10(9H)-one fumarate] prevents mucosal mast cell hyperplasia and intestinal dysmotility in experimental Trichinella spiralis inflammation in the rat. J Pharmacol Exp Ther 2006;319:1104-11, http://dx.doi.org/10.1124/jpet.106.104620.

[24] Enerbäck L, Norrby K. The mast cells. Curr Top Pathol 1989;79:169-204 [PMID:2644084].

[25] Gurish MF, Austen KF. Developmental origin and functional specialization of mast cell subsets. Immunity 2012;37:25-33, http://dx.doi.org/10.1016/j.immuni.2012.07.003.

[26] Aller MA, Arias JL, García-Domínguez J, Arias JI, Durán M, Arias J. Experimental obstructive cholestasis: the wound-like inflammatory liver response. Fibrogenesis Tissue Repair 2008;1:6, http: //dx.doi.org/10.1186/1755-1536-1-6.

[27] Aller MA, Arias JL, Prieto I, Losada M, Arias J. Bile duct ligation: step-by-step to cholangiocyte inflammatory tumorigenesis. Eur J Gastroenterol Hepatol 2010;22:651-61, http://dx.doi.org/10.1097/MEG.0b013e32832e0a2f.

[28] Wulff BC, Wilgus TA. Mast cell activity in the healing wound: more than meets the eye? Exp Dermatol 2013;22:507-10, http://dx.doi.org/10.1111/exd.12169.

[29] Douaiher J, Succar J, Lancerotto L, Gurish MF, Orgill DP, Hamilton MJ, Krilis SA, Stevens RL. Development of mast cells and importance of their tryptase and chymase serine proteases in inflammation and wound healing. Adv Immunol 2014;122:211-52, http://dx.doi.org/10.1016/B978-0-12-800267-4.00006-7.

[30] Wilgus TA, Wulff BC. The importance of mast cells in dermal scarring. Adv Wound Care (New Rochelle) 2014;3:356-65.

[31] Aller MA, Martinez V, Corcuera MT, Benito J, Traver E, Gómez-Aguado F, Vergara P, Arias J. Liver impairment after portacaval shunt in the rat: the loss of protective role of mast cells? Acta Histochem 2012;114:301-10, http://dx.doi.org/10.1016/j.acthis.2011.06.011.

[32] Yoo JM, Yang JH, Kim YS, et al. Inhibitory effects of viscum coloratum extract on IgE/antigen-activated mast cells and mast cell-derived inflammatory mediatoractivated chondrocytes. Molecules 2016;22:E37, http://dx.doi.org/10.1097/MIB.0000000000000892.

[33] Girolamo F, Coppola C, Ribatti D. Immunoregulatory effect of mast cells influenced by microbes in neurodegenerative diseases. Brain Behav Immun 2017;65:68-89, http://dx.doi.org/10.1016/j.bbi.2017.06.017.

[34] Farrell DJ, Hines JE, Walls AF, Kelly PJ, Bennett MK, Burt AD. Intrahepatic mast cells in chronic liver diseases. Hepatology 1995;22(4 Pt 1):1175-81 [PMID: 7557869].

[35] Armbrust T, Batusic D, Ringe B, Ramadori G. Mast cells distribution in human liver disease and experimental rat liver fibrosis.
Indications for mast cell participation in development of liver fibrosis. J Hepatol 1997;26:1042-54 [PMID:9186835].

[36] Yamashiro M, Kouda W, Kono N, Tsuneyama K, Matsui O, Nakanuma Y. Distribution of intrahepatic mast cells in various hepatobiliary disorders. An immunohistochemical study. Virchows Arch 1998;433:471-9 [PMID: 9849863].

[37] Matsunaga Y, Terada T. Mast cell subpopulations in chronic inflammatory hepatobiliary diseases. Liver 2000;20:152-6 [PMID: 10847484].

[38] Viggiano TR, Gostout CJ. Portal hypertensive intestinal vasculopathy: a review of the clinical, endoscopic, and histopathologic features. Am J Gastroenterol 1992;87:944-54 [PMID: 1642217].

[39] Aller MA, Arias N, Blanco-Rivero J, Arias JL, Arias J. Hepatic encephalopathy: Sometimes more portal than hepatic. J Gastroenterol Hepatol 2018, http://dx.doi.org/10.1111/jgh.14514 [Epub ahead of print].

[40] Gupta K, Harvima IT. Mast cell-neural interactions contribute to pain and itch. Immunol Rev 2018;282:168-87, http://dx.doi.org/10.1111/imr.12622.

[41] Wang HW, Tedla N, Lloyd AR, Wakefield D, McNeil PH. Mast cell activation and migration to lymph nodes during induction of an immune response in mice. J Clin Invest 1998;102:1617-26, http://dx.doi.org/10.1172/JCI3704.

[42] Elieh Ali Komi D, Grauwet K. Role of mast cells in regulation of $\mathrm{T}$ Cell Responses in experimental and clinical settings. Clin Rev Allergy Immunol 2018;54:432-45, http://dx.doi.org/10.1007/s12016-017-8646-z.

[43] Aller MA, Prieto I, Argudo S, de Vicente F, Santamaría L, de Miguel MP, Arias JL, Arias J. The interstitial lymphatic peritoneal mesothelium axis in portal hypertensive ascites: when in danger, go back to the sea. Int J Inflam 2010;2010:148689, http://dx.doi.org/10.4061/2010/148689.

[44] de Vries VC, Pino-Lagos K, Nowak EC, et al. Mast cell condition dendritic cell to mediate allograft tolerance. Immunity 2011;35:550-61, http://dx.doi.org/10.4049/jimmunol.1202567.

[45] de Vries VC, Le Mercier I, Nowak EC, Noelle RJ. Studyng mast cells in peripheral tolerance by using a skin transplantation model. Methods Mol Biol 2015;1220:461-86, http: / /dx.doi.org/10.1007/978-1-4939-1568-2_28.

[46] Kurashima $\mathrm{Y}$, Kiyono $\mathrm{H}$. New era for mucosal mast cells: their roles in inflammation allergic immune response and adjuvant development. Exper Mol Med 2014;46:e83, http://dx.doi.org/10.1038/emm.2014.7.

[47] Galli SJ, Tsai M. Mast cell: versatile regulators of inflammation tissue remodeling, host defense and homeostasis. J Dermatol Sci 2008;49:7-19, http://dx.doi.org/10.1016/j.jdermsci.2007.09.009.

[48] Da Silva EZM, Jamur MC, Oliver C. Mast cell function: A new vision of an old cell. J Histochem Cytochem 2014;62:698-738, http://dx.doi.org/10.1369/0022155414545334.

[49] Jalan R, Yuraydin C, Bajaj JS, Acharya SK, Arroyo V, Lin HC, Gines P, Kim WR, Kamath PS. World Gastroenterology Organization Working Party. Toward an improved definition of acuteon-chronic liver failure. Gastroenterology 2014;147:4-10, http://dx.doi.org/10.1053/j.gastro.2014.05.005. 